\title{
CrystEngComm
}

Check for updates

Cite this: CrystEngComm, 2019, 21, 1267

Received 12th October 2018,

Accepted 11th January 2019

DOI: $10.1039 / c 8 c e 01744 a$

rsc.li/crystengcomm

\section{Innovative visualization of the effects of crystal morphology on semiconductor photocatalysts. Tuning the Hückel polarity of the shape-tailoring agents: the case of $\mathrm{Bi}_{2} \mathrm{WO}_{6} \dagger$}

\author{
Zsolt Kása, ${ }^{\text {ab }}$ Lucian Baia, (D) ${ }^{\text {cd }}$ Klára Magyari, ${ }^{d}$ Klára Hernádib and Zsolt Pap (iD *ad
}

\section{Introduction}

Semiconductor oxides, such as titanium dioxide $\left(\mathrm{TiO}_{2}\right)$ and zinc oxide ( $\mathrm{ZnO})$, are still widely used as photocatalysts owing to their high activity, ${ }^{1}$ low $\operatorname{cost}^{2}$ and environmentally friendly features, ${ }^{3}$ such as non-toxicity and biological and chemical inertness. ${ }^{4,5}$ To date, $\mathrm{TiO}_{2}$ has undoubtedly proven to be the best photocatalyst for the oxidative decomposition of many organic compounds under UV irradiation. ${ }^{6}$ Unfortunately, the band gap of the pure anatase titanium dioxide is relatively large $(\approx 3.2 \mathrm{eV})^{7}$ compared with $\mathrm{Bi}_{2} \mathrm{WO}_{6}(\approx 2.7 \mathrm{eV})$, showing

\footnotetext{
${ }^{a}$ Institute of Environmental Science and Technology, University of Szeged, Tisza Lajos blvd. 103, HU-6725, Szeged, Hungary. E-mail: pzsolt@chem.u-szeged.hu, pap.zsolt@phys.ubbcluj.ro

${ }^{b}$ Department of Applied and Environmental Chemistry, University of Szeged, 6720 Szeged, Rerrich Béla sqr., HU-6720, Szeged, Hungary

${ }^{c}$ Nanostructured Materials and Bio-Nano-Interfaces Centre, Interdisciplinary Research Institute on Bio-Nano-Sciences, Babeș-Bolyai University, Treboniu Laurian Str. 42, RO-400271, Cluj-Napoca, Romania

${ }^{d}$ Faculty of Physics, Babeș-Bolyai University, M. Kogălniceanu str. 1, RO-400084

Cluj-Napoca, Romania

$\dagger$ Electronic supplementary information (ESI) available. See DOI: 10.1039/ c8ce01744a
}

that $\mathrm{Bi}_{2} \mathrm{WO}_{6}$ is excitable under visible light irradiation, and making possible the exploitation of the visible light emission component in sunlight. ${ }^{8-10}$

However, before entering in details concerning $\mathrm{Bi}_{2} \mathrm{WO}_{6}$, it should be mentioned first that photocatalytic-based investigations have experienced multiple booms, resulting in an astonishing number of publications, including many great reviews, due to the intensive development of shape-tailored photocatalytic materials, ${ }^{11}$ which is good in terms of progress but is disadvantageous in terms of the important details, such as the clear relationship between a shape-tailoring agent's structure, the obtained morphology and activity. Although, there are formation mechanisms proposed ${ }^{12,13}$ in nearly each of the works considered here, none of them discuss the structure of the shape-tailoring agents, moreover they provide no quantification considering this issue.

A large variety of $\mathrm{Bi}_{2} \mathrm{WO}_{6}$ crystal geometries can be obtained by using shape-controlling crystallization, including nanorods, ${ }^{14}$ nanoplates ${ }^{15}$ and disc- and fiber-like ${ }^{16}$ particles. However, the most commonly obtained shape is the so called rose-like hierarchical structure, which is built from individual plates. ${ }^{17,18}$ To obtain this complex shape, surfactants are necessary such as PVP (polyvinylpyrrolidone), ${ }^{19}$ CTAB 


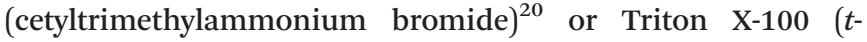
octylphenoxypolyethoxyethanol). ${ }^{21}$ Also, other shapecontrolling agents have been reported, such as thiourea, thioacetamide, urea and glycine..$^{22-24}$ In some cases, just varying the $\mathrm{pH}$ value of the reaction mixture was found to be sufficient to control the shape of the crystals. ${ }^{25}$ All of these shapetailoring approaches were applied to increase the photocatalytic activity of the obtained nanomaterials, but they also showed other effects, including band gap changes ${ }^{26}$ or changes in the amount of the surface defects. ${ }^{27,28}$

The number of studies investigating the influence of the non-surfactant shape-tailoring agents' molecular structure in the case of bismuth tungstate is much smaller compared to titanium dioxide, ${ }^{29}$ although several other interesting approaches have also been investigated, such as shape-tailoring by $\mathrm{pH}$ manipulation. ${ }^{30}$

This is rather unusual, as the use of non-surfactant additives are very important in the Ostwald-ripening process. Therefore, controlling the polarity of the additive molecules could allow a rigorous control of the crystal morphology and thus, of the activity. Therefore, in this study, the effects of the molecular structure of the additive molecules were investigated on the morpho-structural and photocatalytic properties of $\mathrm{Bi}_{2} \mathrm{WO}_{6}$. Furthermore, the quantification of the molecular structure in polarity terms of the additives and its relationship with the morphology and activity were also considered and explored.

\section{Experimental}

\subsection{Materials}

All the chemicals used were of analytical grade and applied without further purification. Bismuth(III) nitrate pentahydrate $\left(\mathrm{Bi}\left(\mathrm{NO}_{3}\right)_{3} \cdot 5 \mathrm{H}_{2} \mathrm{O}\right.$, purity $98 \%$ ) and sodium tungstate dihydrate $\left(\mathrm{Na}_{2} \mathrm{WO}_{4} \cdot 2 \mathrm{H}_{2} \mathrm{O}\right.$, purity $\left.99 \%\right)$ were purchased from Alfa Aesar. Triton X-100 (octyl phenol ethoxylate, $\mathrm{C}_{14} \mathrm{H}_{22} \mathrm{O}\left(\mathrm{C}_{2} \mathrm{H}_{4} \mathrm{O}\right)_{n}$, purity $98-100 \%$, TRX) was purchased from Merck. Acetic acid $\left(\mathrm{C}_{2} \mathrm{H}_{4} \mathrm{O}_{2}\right.$, concentration $\left.36 \%\right)$ was purchased from Nordic Invest. Milli-Q water was used throughout the experimental process. The used additives were the following:

- Thiourea (TU) $\left(\mathrm{CH}_{4} \mathrm{~N}_{2} \mathrm{~S}\right.$, purity >99\%) from Nordic Chem,

- Urea (U) $\left(\mathrm{CH}_{4} \mathrm{~N}_{2} \mathrm{O}\right.$, purity $\left.>99 \%\right)$ from Sigma-Aldrich,

- Thioacetamide (TAA) $\left(\mathrm{C}_{2} \mathrm{H}_{5} \mathrm{NS}\right.$, purity $\left.>99 \%\right)$ from Fluka,

- Acetamide (AA) $\left(\mathrm{C}_{2} \mathrm{H}_{5} \mathrm{NO}\right.$, purity $\left.>99 \%\right)$ from SigmaAldrich,

- Acetone (AC) $\left(\mathrm{C}_{6} \mathrm{H}_{6} \mathrm{O}\right.$, purity $\left.>99.8 \%\right)$ from VWR,

- Glycine (G) $\left(\mathrm{C}_{2} \mathrm{H}_{5} \mathrm{NO}_{2}\right.$, purity $\left.>99 \%\right)$ from Sigma-Aldrich,

- Alanine (A) $\left(\mathrm{C}_{3} \mathrm{H}_{7} \mathrm{NO}_{2}\right.$, purity $\left.>99 \%\right)$ from ReAnal,

- Phenylalanine (FA) $\left(\mathrm{C}_{9} \mathrm{H}_{11} \mathrm{NO}_{2}\right.$, purity $\left.>99 \%\right)$ from SigmaAldrich.

\subsection{Synthesis of $\mathrm{Bi}_{2} \mathrm{WO}_{6}$ microparticles}

In a typical synthesis, $2.13 \mathrm{~g} \mathrm{Bi}\left(\mathrm{NO}_{3}\right)_{3} \cdot 5 \mathrm{H}_{2} \mathrm{O}$ was dissolved in $43 \mathrm{~mL} 36 \%$ acetic acid, yielding a transparent solution (solution A). Solution B was prepared by dissolving $0.71 \mathrm{~g} \mathrm{Na}_{2} \mathrm{WO}_{4}$ $\cdot 2 \mathrm{H}_{2} \mathrm{O}$ in $69 \mathrm{~mL}$ Milli-Q water, followed by the addition of $0.62 \mathrm{~mL}$ Triton $\mathrm{X}-100$ under vigorous stirring. Finally, the shape-controlling agents were individually added to the metal ion/surfactant aqueous solution in the same concentration (0.625 mM).

Solution B was added slowly, dropwise into solution A under vigorous stirring. After the appearance of a yellowish precipitation, the amorphous suspension was stirred for an additional $1 \mathrm{~h}$ at room temperature, then sealed in a $174 \mathrm{~mL}$ Teflon-lined stainless-steel autoclave, maintained at $180{ }^{\circ} \mathrm{C}$ for $15 \mathrm{~h}$ and then cooled to room temperature naturally. The obtained dispersion was centrifuged at $3000 \mathrm{rpm}$ for $10 \mathrm{~min}$ and washed with absolute ethanol and Milli-Q water 5 times, before being finally dried at $80^{\circ} \mathrm{C}$ for $24 \mathrm{~h}$.

These samples were coded as follows: TU, TU + TRX, U, U + TRX, TAA, TAA + TRX, AA, AA + TRX, A, A + TRX, FA, FA + TRX, G, G + TRX, AC, AC + TRX, TRX and PURE, where the first letter marks the catalysts obtained in the presence of additives with various structures (the specifications and the abbreviations of the additives can be found in section 2.1.), while the TRX abbreviation stands for Triton X-100. PURE was the name given to the catalyst made without any additives.

Thus, two main sample series were fabricated. In all of them, the reference term was the polarity of the carbon-chalcogen (O or $S$ ) double bond. In one case, the thiourea/urea/ acetone triangle's (AC, TAA, AA, U, TU) variations were tested; while in the other case, the carbon chain (G, A, FA) of the amino acids was varied to verify if alternative shape-tailor approaches could be linked in the same way to the activity and morphology.

\subsection{Methods and instrumentations}

$\mathrm{X}$-ray diffraction (XRD) measurements were used to determine the crystalline phase composition and to estimate the mean crystallite size of the samples. The XRD patterns were recorded using a Rigaku MiniFlex II powder diffractometer using $\mathrm{Cu}-\mathrm{K} \alpha$ radiation $(\lambda=0.15406 \mathrm{~nm})$, equipped with a graphite monochromator. The diffractograms were recorded in a $2 \theta^{\circ}$ range from $20^{\circ}$ to $80^{\circ}$, with a speed of $3\left(2 \theta^{\circ}\right) \mathrm{min}^{-1}$ Scherrer's equation was applied to evaluate the primary crystallite size. The morphology of the particles was analysed by cold field-emission scanning electron microscopy (SEM) (Hitachi S-4700 Type II) operating at $10 \mathrm{kV}$. The surface profile of the particles was evaluated by considering the image of 50 particles and applying the profile plot function in ImageJ software.

The particle geometry was approached by utilizing the rose similarity decay constant $\left(R_{\mathrm{SDC}}\right)$, a parameter developed for this special case to quantify morphological issues. However, before evaluation, a pre-definition of rose shape was emitted to distinguish non-rose like and rose-like geometries:

- Diameter asymmetry permitted (circularity): 1 : 1.2 .

- Homogeneous building blocks: 20\% variance in crystal size. 
The $R_{\mathrm{SDC}}$ value was created to approximate the hierarchical crystal geometries and for quantification of the geometry. It was determined as follows:

$$
R_{\mathrm{SDC}}=\sum_{i=1}^{n} \frac{\left|N_{\mathrm{LMI}}-\frac{\sum_{i=1}^{n} N_{\mathrm{LMI}}}{n}\right|}{N_{\mathrm{LMI}}}
$$

$N_{\text {LMI }}$ is the number of local maxima at a given surface profile.

$n$ is the number of acquired profiles, with a minimum of 4 .

$R_{\text {SDC }}$ is a value between 0 and $n$. If the obtained value is 0 , then we have a geometrically perfect rose shape; while if this value equals $n$ (in our case 4 , the hierarchical particle is not rose like). The steps of the evaluation are illustrated in Fig. 1. Briefly, the SEM micrographs were converted to black and white images. Four total profiling lines were drawn for a single particle and their profile evaluated, using the black and white oscillation in the specific image. The data was collected, and the above-mentioned equation was applied. Although, this approach may link in a very simple way the photoactivity to a quantified morphology specific value, it does not entirely replace the classical structure-morphologyactivity analytical approach, but instead provides a fast and reliable insight on the existence of the relationship between the morphology and activity (black-box approach).

The specific surface areas of the catalysts were determined by $\mathrm{N}_{2}$ adsorption at $77 \mathrm{~K}$, using a BELCAT-A device. The specific surface area was calculated via the BET method.
A JASCO-V650 spectrophotometer with an integration sphere (ILV-724) was used to record the diffuse reflectance spectra of the synthesized $\mathrm{Bi}_{2} \mathrm{WO}_{6}$ crystals in the 250-800 $\mathrm{nm}$ wavelength range. The diffuse reflectance spectra were differentiated as a function of the wavelength $(\mathrm{d} R / \mathrm{d} \lambda)$. The derivation was performed between $300 \mathrm{~nm}$ and $650 \mathrm{~nm}$, in order to evaluate the possible electron-transition bands. ${ }^{31}$ Kubelka-Munk/Tauc plots were also used to determine the band-gap values of the photocatalysts, but due to the uncertain values provided by this method, they were omitted from the interpretation of the results, but they are included in Table 1.

The infrared spectra were recorded using a Jasco 6000 (Jasco, Tokyo, Japan) spectrometer, at room temperature, in the range $400-4000 \mathrm{~cm}^{-1}$ and at a spectral resolution of 4 $\mathrm{cm}^{-1}$ using the well-known $\mathrm{KBr}$ pellet technique.

\subsection{Photocatalytic activity}

The photocatalytic activity was determined by the photodegradation of rhodamine $\mathrm{B}(\mathrm{RhB})$ at $25^{\circ} \mathrm{C}$. $6 \times 6 \mathrm{~W}$ fluorescent UV lamps $\left(\lambda_{\max }=365 \mathrm{~nm}\right)$ or $4 \times 24 \mathrm{~W}$ conventional energy saving lamps $\left(\lambda_{\max }>400 \mathrm{~nm}\right)$ with a cut-off filter $\left(\mathrm{NaNO}_{2}\right)$ were used as the light source. Aqueous suspension of $\mathrm{RhB}\left(100 \mathrm{~mL} 5 \times 10^{-5} \mathrm{~mol} \mathrm{dm}{ }^{-3}\right)$ and $0.1 \mathrm{~g} \mathrm{Bi}_{2} \mathrm{WO}_{6}$ powder were placed in a vessel and suspended using an ultrasonication bath. Prior to irradiation, the suspension was stirred in the dark for $30 \mathrm{~min}$ to ensure adsorption/desorption equilibrium. After the lamps were switched on, and at every $30 \mathrm{~min}, 2 \mathrm{~mL}$ of the suspension was collected, centrifuged and filtered. The concentration of the rhodamine B was determined using an Agilent 8453 UV-vis spectrophotometer (detection wavelength $=553 \mathrm{~nm}$ ). The spectrum of the lamps are shown in the ESI† (Fig. S1).

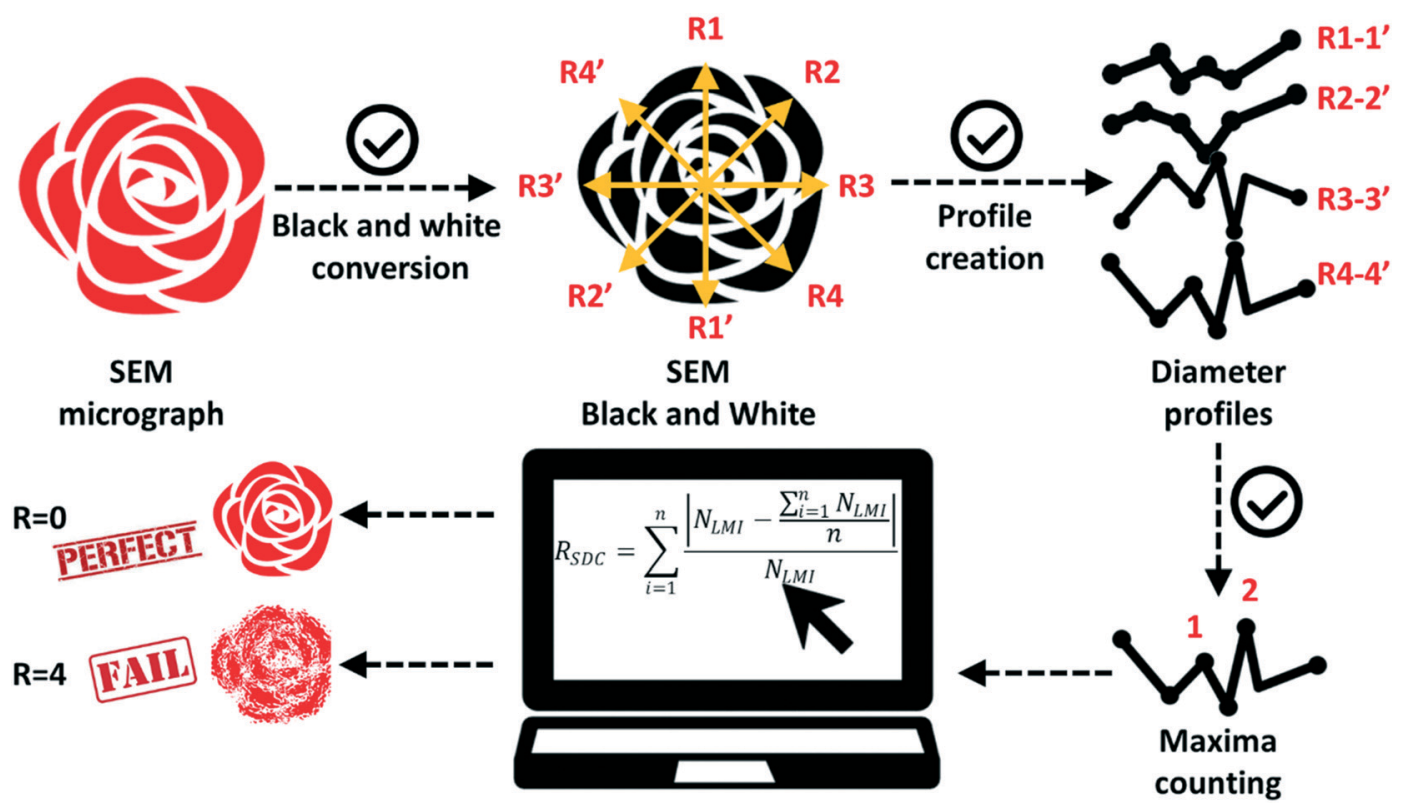

Fig. 1 The methodology applied in the determination process of the rose similarity decay constant $\left(R_{\mathrm{SDC}}\right)$ : a schematic representation. 
Table 1 The primary mean crystallite size, the band-gap energy and the first derivative spectra maximum values shown together with the specific surface area of all the samples investigated throughout this work

\begin{tabular}{lllll}
\hline $\begin{array}{l}\text { Sample } \\
\text { name }\end{array}$ & $\begin{array}{l}\text { Primary crystallite } \\
\text { size }(\mathrm{nm})\end{array}$ & $\begin{array}{l}\text { Band gap }- \\
\mathrm{KM}^{*}(\mathrm{eV})\end{array}$ & $\begin{array}{l}\mathrm{d} R / \mathrm{d} \lambda \\
\text { maximum } \\
(\mathrm{nm})\end{array}$ & $\begin{array}{l}S_{\mathrm{BET}} \\
\left(\mathrm{m}^{2} \mathrm{~g}^{-1}\right)\end{array}$ \\
\hline TAA & 16.9 & 2.79 & 412 & 27 \\
TAA + TRX & 17.2 & 2.96 & 415 & 32 \\
TU & 17.6 & 2.79 & 417 & 23 \\
TU + TRX & 16.1 & 2.84 & 401 & 15 \\
AA & 16.2 & 2.75 & 419 & 9 \\
AA + TRX & 15.6 & 2.78 & 413 & 11 \\
U & 15.8 & 2.85 & 422 & 10 \\
U + TRX & 16.2 & 2.82 & 413 & 16 \\
Ac & 16.4 & 2.79 & 411 & 8 \\
Ac + TRX & 17.0 & 2.81 & 412 & 12 \\
G & 16.9 & 2.84 & 420 & 9 \\
G + TRX & 17.1 & 2.77 & 408 & 11 \\
A & 17.0 & 2.84 & 422 & 13 \\
A + TRX & 16.2 & 2.84 & 417 & 9 \\
FA & 14.8 & 2.83 & 418 & 9 \\
FA + TRX & 16.6 & 2.84 & 414 & 10 \\
\hline
\end{tabular}

\section{Results and discussion}

\subsection{Photocatalytic activity under UV and visible light irradiation}

As a high number of samples were obtained, in the first instance the photoactivity under both UV and visible light irradiation is discussed for treating a well-known model pollutant, rhodamine B. Furthermore, the materials obtained in the presence of Triton-X-100 showed different photocatalytic activity. Also, it seems that all the photocatalysts degraded $\mathrm{RhB}$ more efficiently under visible light irradiation than un- der UV (exception AA + TRX). However, the degradation results obtained under UV and under visible light could not be directly compared, as the light source output power was different. Therefore, the samples' photocatalytic performance analysis was carried out separately for UV and separately for visible light. The achieved photocatalytic performances are illustrated in Fig. 2.

Under UV light irradiation, all the catalysts showed higher photocatalytic activity. These were all synthesized in the presence of Triton X-100, except for two samples TAA $(69.7 \%)$ and G (66.6\%), which showed the best activity. G + TRX degraded the lowest amount of RhB (25.1\%), even less than the sample PURE (29.3\%).

However, under visible light illumination, a completely different activity sequence of photoactivity was established. G + TRX was the most efficient photocatalyst (84.6\%). Furthermore, two samples were below the average photocatalytic performance, but were over the average performance under UV (TU + TRX: $57.2 \%$ and AA + TRX: $57.0 \%$ ).

Besides the above-mentioned main trends, it seems that no correlation could be found in the large amount of degradation data. However, there was a main parameter that varied indirectly, namely the electron distribution in the shapetailoring agents (except for TRX, which was present or absent in a specific synthesis). Hence, quantification of the electron distribution was carried out using the Hückel calculation method for the $\mathrm{C}=\mathrm{O}$ (or $\mathrm{S}$ ) bond (not the molecule polarity) in the investigated compounds, which possessed the following general formula: $\mathbf{R}_{\mathbf{1}}-\mathbf{C O}-\mathbf{R}_{\mathbf{2}}$.

By pairing the activity with the Hückel polarity, two behaviour groups were detected and thus two series of measurements are discussed herein:

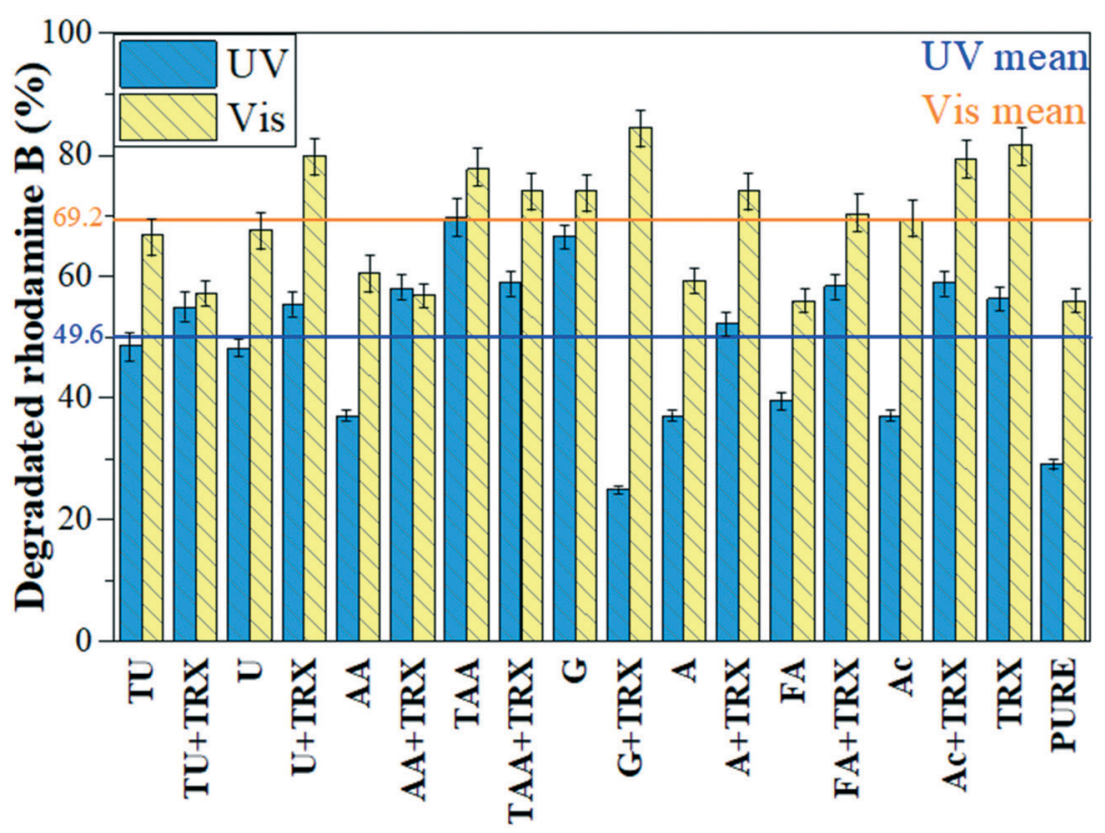

Fig. 2 The photocatalytic activity under UV- and visible light of $\mathrm{Bi}_{2} \mathrm{WO}_{6}$ photocatalysts synthesized using different shape-tailoring agents. The visible light activity of the obtained nanomaterials was higher compared to the UV performances. The measured performances were recorded after $2 \mathrm{~h}$ irradiation. 
- Case 1: $\mathbf{R}_{\mathbf{1}}$-CO- $\mathbf{R}_{2}$ - optimization, where $\mathbf{R}_{1}$ and $\mathbf{R}_{2}$ are $\mathrm{CH}_{3}-$ or $\mathrm{NH}_{2}-$ and $=\mathrm{O}$ is replaced with $=\mathrm{S}$;

- Case 2: $\mathbf{N H}_{\mathbf{2}}-\mathbf{C H R} \mathbf{R}_{\mathbf{1}}-\mathbf{C O}-\mathbf{R}_{\mathbf{2}}$ - reconsideration of the hydrocarbon chain impact investigation as follows: where $\mathrm{R}_{1}$ is $\mathrm{H}-$, $\mathrm{CH}_{3}-$, or $\mathrm{C}_{6} \mathrm{H}_{5^{-}}$, and $\mathrm{R}_{2}$ is $-\mathrm{OH}$ in all cases;

- TRX samples $v s$. samples with the absence of TRX - covering the influence of the additional shape-tailoring agent Triton X-100.

In case 1 , it was found that by increasing the polarity of the shape-tailoring molecule from 0.27 to 0.52 , the activity of the obtained samples decreased both under UV and visible light irradiation. The presence of TRX extinguished the impact of $\mathbf{R}_{\mathbf{1}}-\mathbf{C O}-\mathbf{R}_{\mathbf{2}}$ when the UV light activity was considered (activity average of 52-58\%); while in the case of visible light activity, TRX caused a local minimum to appear. It should be noted that samples denoted here with a "U" represent an exception and are marked differently in Fig. 3.

In case 2 , with the polarity increase of the $\mathbf{N H}_{\mathbf{2}}-\mathbf{C H R}-\mathbf{C O}-$ $\mathbf{R}_{\mathbf{2}}$ molecule, the same activity trend was observed (Fig. 4). In this investigation group only, UV-TRX showed an increasing trend. However, in this case, it was also confirmed that a polarity increase of the additive molecule resulted in a decreased activity. Moreover, this reinforcement of the results in case 1 is rather important, because it shows different molecular base structures' polarity could be varied by changing the hydrocarbon side chain. To enlighten which structural or morphological properties can result in such a difference, multiple investigations were carried out.

\subsection{X-ray diffraction (XRD)}

All the investigated samples showed diffraction peaks corresponding to the orthorhombic crystal phase of russellite
$\mathrm{Bi}_{2} \mathrm{WO}_{6}$ (Fig. 5). The following diffraction peaks were obtained: (113), (200) and (020), (206), (220), (226), (313), (133), (333), (240) and (420) planes, respectively (JCPDS card number: 79-2381)

The primary crystallite sizes were estimated using the Scherrer equation. The primary particle size values of the crystalline bismuth tungstates were between $14.8 \mathrm{~nm}$ and $17.6 \mathrm{~nm}$, within experimental errors. Therefore, it seems that the applied shape-tailoring agents did not significantly affect the primary particle size.

\subsection{Diffuse reflectance spectroscopy (DRS) and $\mathbf{N}_{2}$ adsorption measurements}

As no major differences were found in the XRD patterns of the samples, the next step was to examine the optical properties of the materials. The classic approach of the Tauc-plot was omitted as the data did not show any correlation with the shown activity or with the polarity of the investigated bond. Therefore, the first derivative spectra were investigated in detail. The reference values were the ones obtained in the case of samples TRX and PURE. When the first case was investigated, it was found that, with the polarity increase of $\mathrm{C}=\mathrm{O}$ or $\mathrm{C}=\mathrm{S}$ bonds, the maximum of the $\mathrm{d} R / \mathrm{d} \lambda$ was shifted gradually from $406 \mathrm{~nm}$ to $423 \mathrm{~nm}$ (see Fig. 6), which represented a $0.13 \mathrm{eV}$ red-shift. It should be noted that this was only valid when Triton-X was not applied in the synthesis procedure. When it was applied, the previously mentioned correlation was not present. For case 2 , the same trend was noticed, but this time the increase was more significant when the investigated catalysts were prepared in the presence of Triton X-100. The evidenced shift here was less significant from $408 \mathrm{~nm}$ to $416 \mathrm{~nm}(0.06 \mathrm{eV})$, as shown in Fig. 7 .

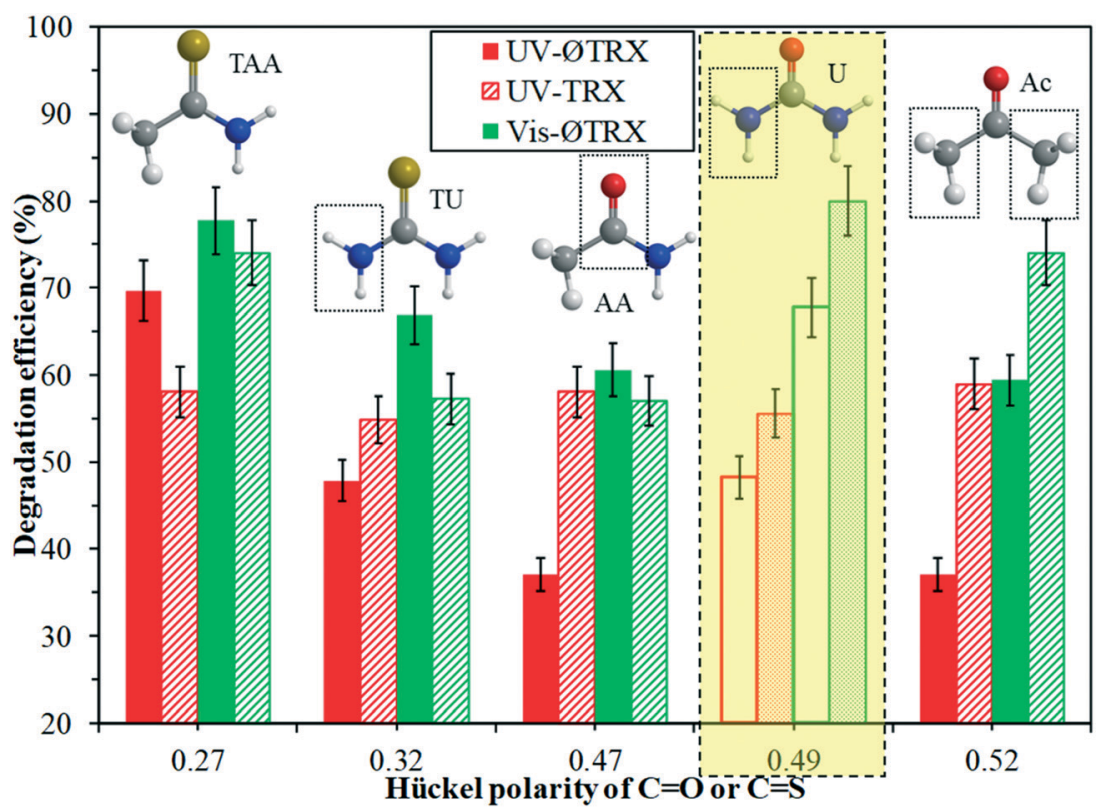

Fig. 3 Rhodamine B photodegradation efficiency (both under UV and visible light) as a function of the Hückel polarity of the used $\mathbf{R}_{\mathbf{1}}$-CO- $\mathbf{R}_{\mathbf{2}}$ molecule during the synthesis of $\mathrm{Bi}_{2} \mathrm{WO}_{6}$. The impact of Triton X-100 was also investigated (as an additional shape-tailoring agent) with the $\varnothing T R X$ and TRX series. 


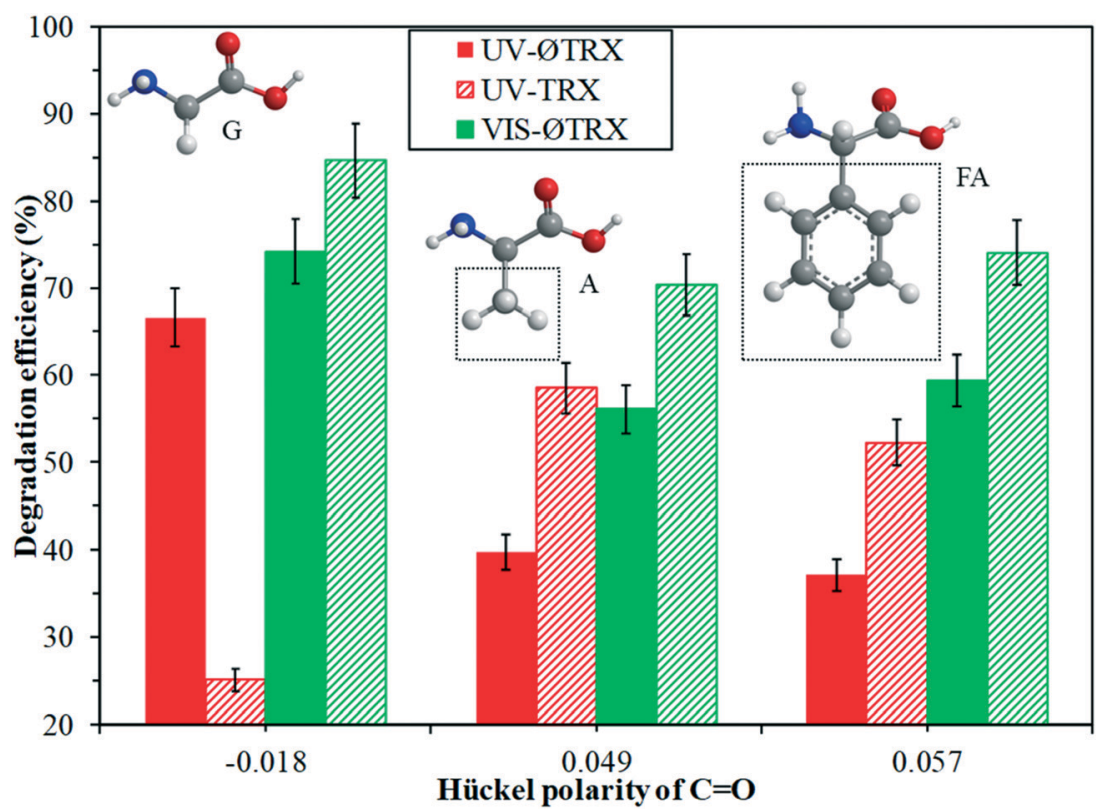

Fig. 4 Rhodamine B photodegradation efficiency (both under UV and visible light) as a function of the Hückel polarity of the used $\mathrm{NH}_{2}-\mathrm{CHR}_{1}$-CO-R molecule during the synthesis of $\mathrm{Bi}_{2} \mathrm{WO}_{6}$. The impact of Triton X-100 was also investigated (as an additional shape-tailoring agent): ØTRX and TRX series.

Specific surface area measurements were carried out to verify if the different additives could influence the surface

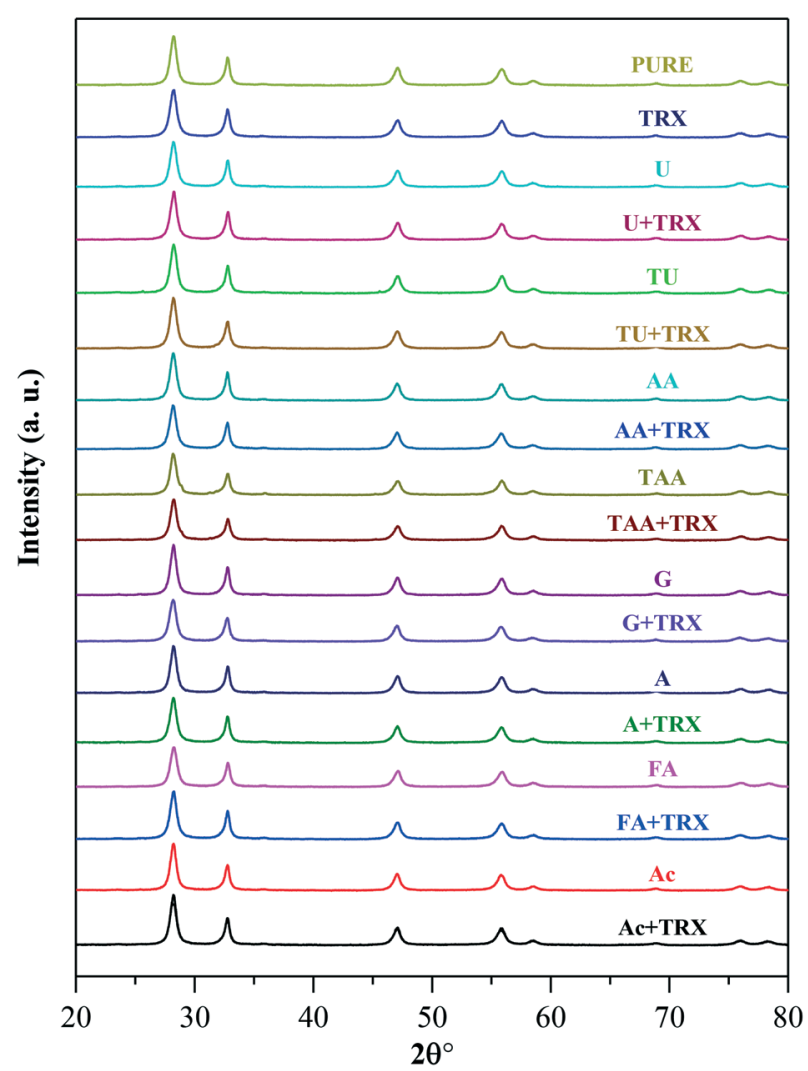

Fig. 5 XRD patterns of all the samples, showing the same crystal phase and nearly the same crystallite size, pointing out that no specific orientation changes were obtained by using the synthesis approach detailed in this work. available for photocatalytic reactions. Also, the influence of the presence of TRX was verified. As the primary crystallite size values were quite low, it was expected that high specific surface area values would be obtained, but it turned out this was not the case. All the specific surface area values were between $32 \mathrm{~m}^{2} \mathrm{~g}^{-1}$ and $8 \mathrm{~m}^{2} \mathrm{~g}^{-1}$, which are actually quite low (Table 1). This suggests the presence of compact hierarchical structures. The first interesting observation was that, in all the cases, the samples obtained in the presence of TRX showed higher specific surface area values than the sample counterparts without TRX, even in the case of the samples PURE vs. TRX (the sample). This was expected as TRX is

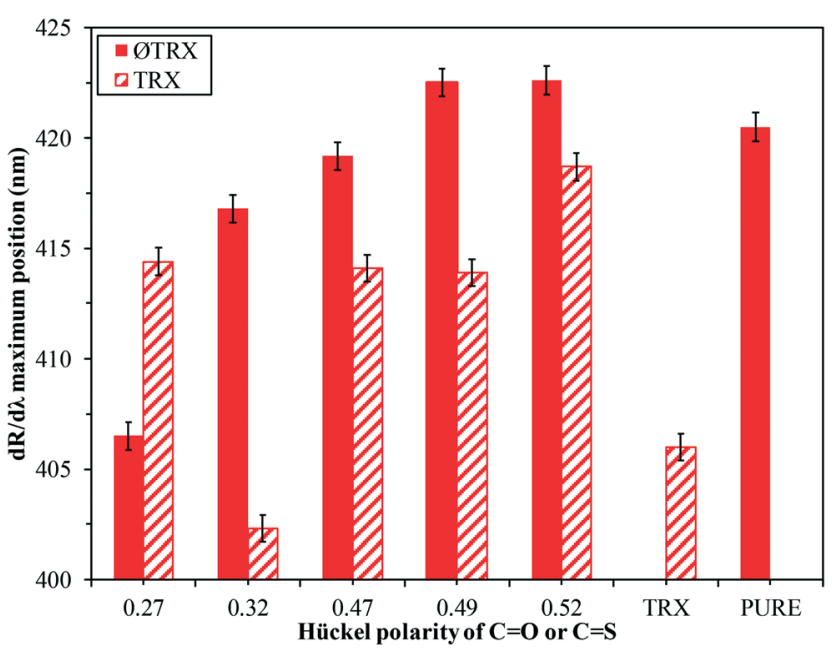

Fig. $6 \mathrm{~d} R / \mathrm{d} \lambda$ peak position values as the $\mathrm{C}=\mathrm{O}$ or $\mathrm{C}=\mathrm{S}$ bonds' Hückel polarity changes in the case of $\mathbf{R}_{\mathbf{1}}-\mathrm{CO}-\mathbf{R}_{\mathbf{2}}$, showing that the polarity is directly related to the optical properties of the nanomaterials, when no Triton-X was applied. 


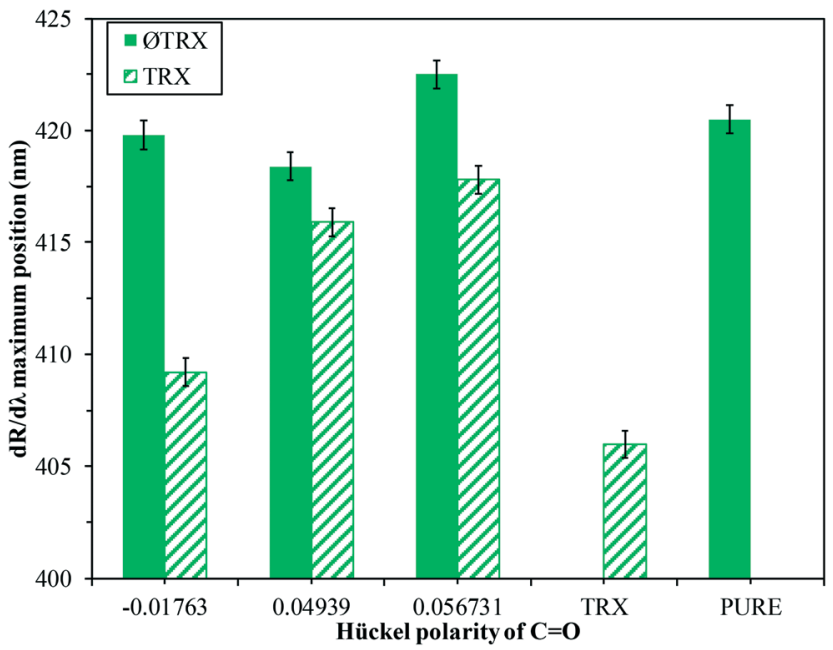

Fig. $7 \mathrm{~d} R / \mathrm{d} \lambda$ peak position values as the $\mathrm{C}=\mathrm{O}$ bonds' Hückel polarity changes in the case of $\mathbf{N H}_{2}-\mathrm{CHR}_{\mathbf{1}}-\mathrm{CO}-\mathbf{R}_{\mathbf{2}}$, where a slight increase in the polarity increased the position of the derivative spectrum maxima.

known to favour the formation and stabilization of small nanoparticles. Just two exceptions were noticed (sample TU and $\mathrm{A}$ and their TRX counterparts).

Another interesting observation was that, as the Hückel polarity of the $\mathrm{C}=$ chalcogen bond increased, the specific surface area decreased concomitantly (Table 1). However, the highest photoactivity was for the samples with a low specific surface area (e.g. AC, G samples and their TRX analogues); therefore, the main reason behind the activity must be elsewhere.

These were the first parameters that showed a clear correlation with the determined Hückel polarity values, without the interference of the exception samples in the observed trends discussed above. However, further important scientific data were needed to validate the correlation and to explain the inconsistencies observed in the activity section. The next step was then to investigate the morphology of the $\mathrm{Bi}_{2} \mathrm{WO}_{6}$ crystals.

\subsection{Effects of the different polarity additives on the morphology}

As discussed before, there were several interesting trends pointed out by the photoactivity of the samples and the optical properties dependent on the Hückel polarity of the carbon-chalcogen (O or S) double bond. Alas, it was necessary to visually investigate the morphological trends that may have arisen (Fig. 8 and 9).

PURE and TRX samples were the ones chosen as the base references, as PURE contained neither Triton X-100 nor other shape-tailoring agents, while TRX contained only the previously mentioned Triton X-100. Without any additives, the SEM micrographs of PURE showed that a spherical hierarchical structure was formed, where the constituent elements' geometry was randomly polyhedral. However, when Triton X-100 was used, lamellar associations of these particles were observed. The surface chemistry and properties of these materials have already been presented in our previous work. ${ }^{32}$
Also, it should be noted here, that throughout the present section, only visible light activity was investigated as $\mathrm{Bi}_{2} \mathrm{WO}_{6}$ is generally referred to as a visible-light-active photocatalyst.

As in the previous sections, two cases are differentiated here. The first one is case $\mathbf{1}: \mathbf{R}_{\mathbf{1}}-\mathbf{C O}-\mathbf{R}_{\mathbf{2}}$, where $\mathbf{R}_{\mathbf{1}}$ and $\mathbf{R}_{\mathbf{2}}$ are $\mathrm{CH}_{3}-$ or $\mathrm{NH}_{2}-$ and $=\mathrm{O}$ was replaced with $=\mathrm{S}$. The first issue was to investigate the integrity of the hierarchical structure. The spherical secondary structure was well preserved, except for TAA and TAA-TRX, while non-rose-shaped samples were also detected, including TRX (Fig. 8). The samples series that did not contain any Triton X-100 showed a very interesting correlation of the surface roughness/profile (evaluated as already shown in Fig. 1), which were directly related with the formed plates and other structures in the hierarchical buildup. As the Hückel-polarity of the $\mathrm{C}=\mathrm{O}$ (or $\mathrm{S}$ ) increases the observed surface roughness goes through a maximum value (Fig. 10), while at the same time, the visible light activity goes through a minimum. Although, this very important result shows the controllability of the morphology by the structure of the shape-tailoring agents, the surface roughness/profile values could not be linked directly. In this sample series, the activity trends were rather more structural dependent, than morphological. However, one sample was some specific exceptions as already discussed in the previous sections: $U$ and $\mathrm{U}+$ TRX. The activities of these two samples could be explainable neither by the structural approach nor by the profiling approach, as discussed here.

Case 2: $\mathbf{N H}_{\mathbf{2}}-\mathbf{C H R} \mathbf{R}_{\mathbf{1}}-\mathbf{C O}-\mathbf{R}_{\mathbf{2}}$ - hydrocarbon chain impact investigation, where $\mathrm{R}_{1}$ was $\mathrm{H}-, \mathrm{CH}_{3}-$ or $\mathrm{C}_{6} \mathrm{H}_{5}-$ and in all the cases $\mathrm{R}_{2}$ was $-\mathrm{OH}$. Also, in this case, the spherical secondary structure was well preserved, while non-rose-shaped samples were also detected, including G-TRX and A-TRX (Fig. 9). This simple sample series was also investigated both by the profiling approach (for the samples without TRX) and by the $R_{\mathrm{SDC}}$ approach (samples with TRX). As the Hückel polarity of the samples increased in the first sample series, the periodicity of the profiles increased as well, following the same trend but showing a continuous increase (observed for the samples without TRX but in case 1). This approach also showed that other structural/morphological influences could be efficiently linked to the activity by the structure of the shape-tailoring agent.

As already stated above, not all activities were explainable by the profiling (current section) or structural/optical approach (sections 3.1.-3.3.). Therefore, the $R_{\mathrm{SDC}}$ was applied for the TRX samples of case 1, which was defined in the experimental section. An interesting dependence was observed; whereby, as the $R_{\mathrm{SDC}}$ value increased (shapes not so close to a rose), the observed visible light activity decreased likewise (Fig. 11), showing that the rose-like structure is an important factor in the activity (the UV activity showed no variation throughout the TRX series). Furthermore, the $R_{\mathrm{SDC}}$ study revealed that both the rose-shape categorized and non-rose shape categorized samples showed the same trend, namely that, with the increase of $R_{\mathrm{SDC}}$, the visible-light-driven photoactivity decreases. In this way, a more complex morphological criterion was shown, which could be easily paired with the 


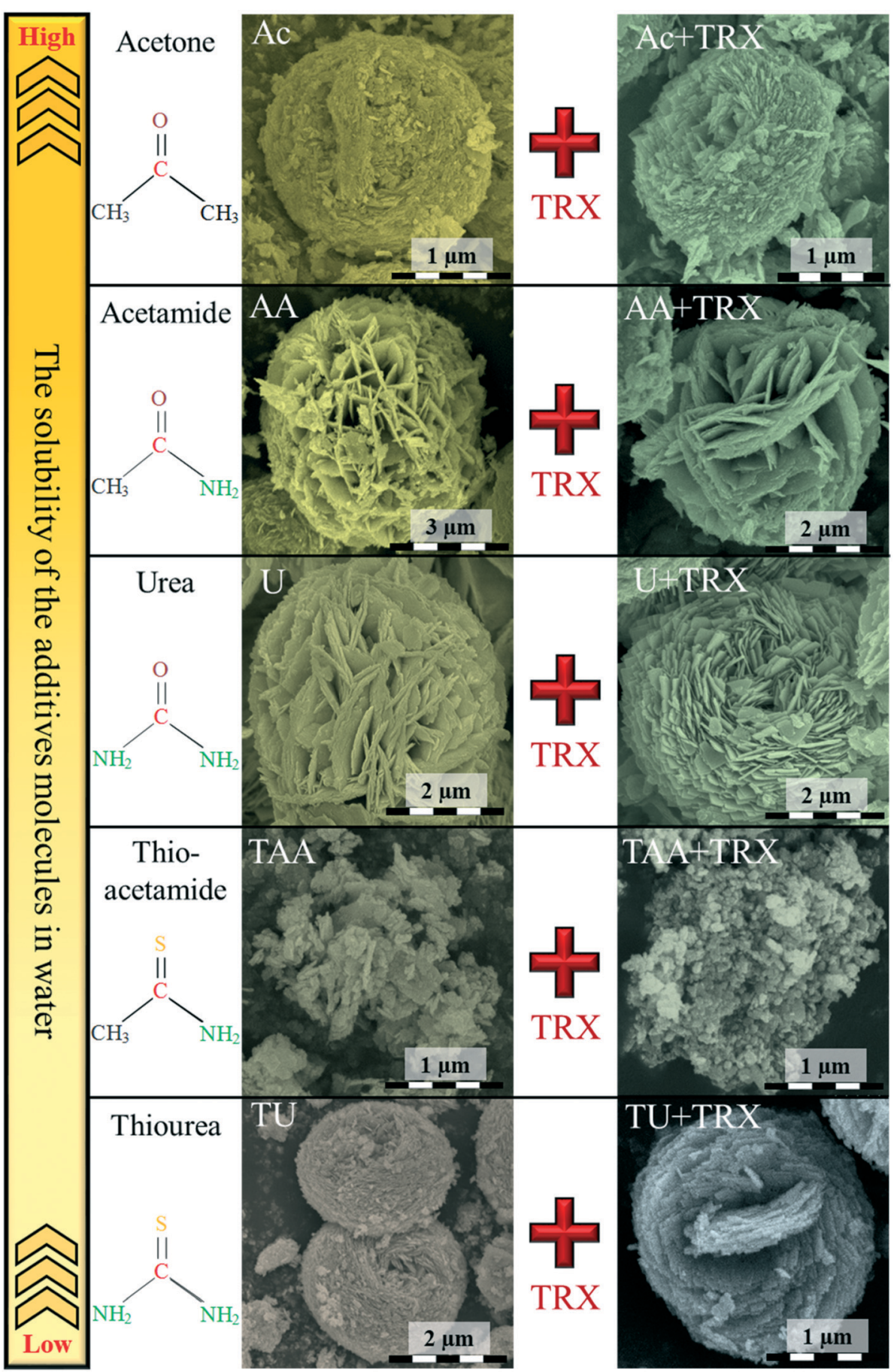

Fig. 8 Morphological changes of $\mathrm{Bi}_{2} \mathrm{WO}_{6}$ induced by the change of the shape-tailoring agents' structure, in the case of $\mathbf{R}_{\mathbf{1}}-\mathrm{CO}-\mathrm{R}_{\mathbf{2}}$, where $\mathrm{R}_{1}$ and $\mathrm{R}_{2}$ were $\mathrm{CH}_{3}$ - or $\mathrm{NH}_{2}-$ and $=\mathrm{O}$ was replaced with $=\mathrm{S}$.

visible light activity values and could help explain the visiblelight-activity trends throughout the TRX series and samples $\mathrm{U}$ and TRX.

\subsection{Infrared analysis}

Our last step in the analysis of the shape-tailoring agents and their relationship with the obtained photocatalysts relates to their anchoring on the surface of the catalyst and their persistence. We already showed that the surface purity of this material is not crucial in terms of the photocatalytic activity. $^{30}$ Therefore, it is an ideal material to use to investigate the persistence of the additive molecules on the surface of the catalysts, which could aid gaining an understanding of what happens to these organic compounds after hydrothermal treatment. 


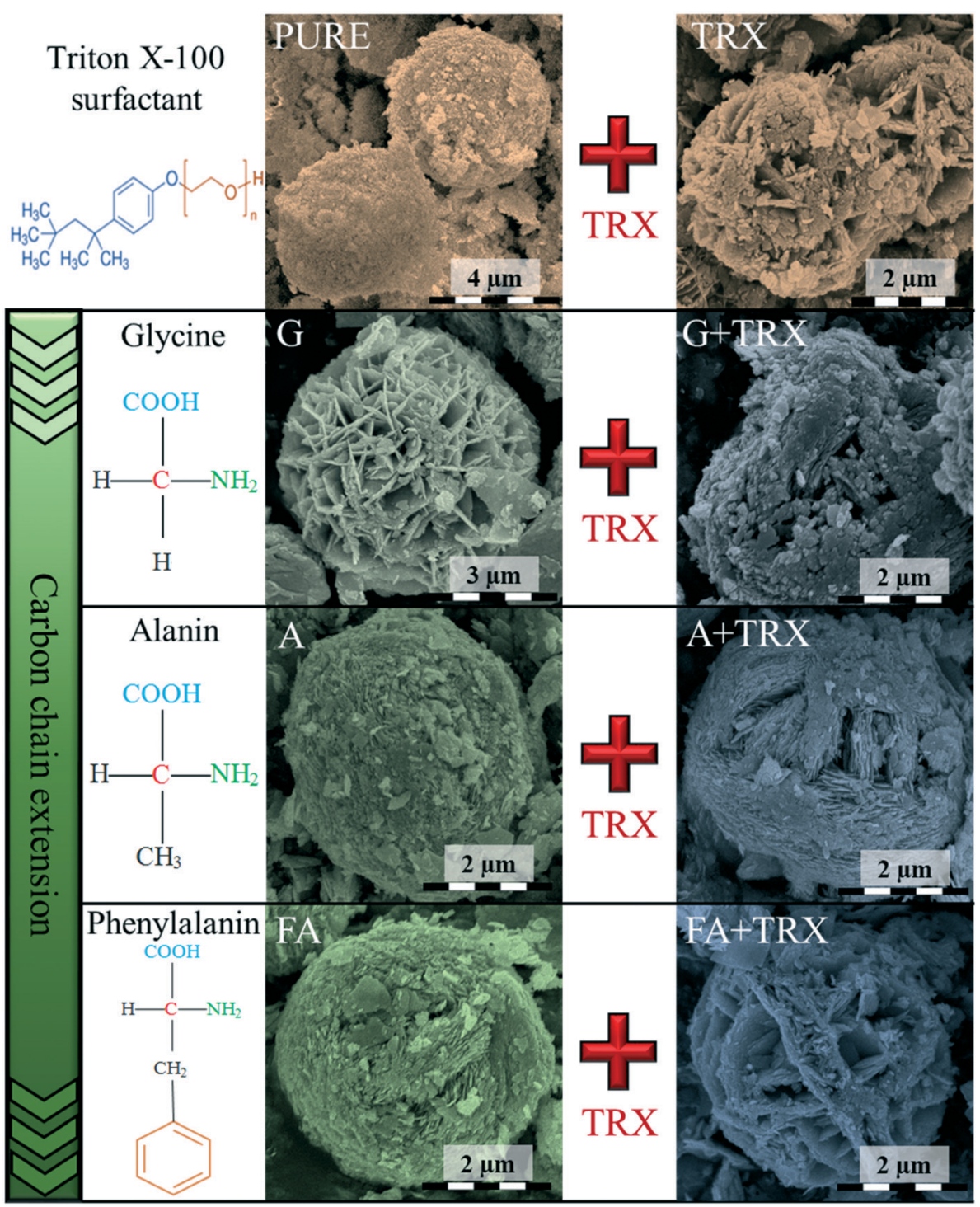

Fig. 9 Morphological changes of $\mathrm{Bi}_{2} \mathrm{WO}_{6}$ induced by the change of the shape-tailoring agents' structure, in the case of the $\mathrm{NH}_{2}-\mathrm{CHR}_{1}-\mathrm{CO}-\mathrm{R}_{2}$ molecule, where $\mathrm{R}_{1}$ was $\mathrm{H}_{-}, \mathrm{CH}_{3}-$ or $\mathrm{C}_{6} \mathrm{H}_{5^{-}}$and in all the cases where $\mathrm{R}_{2}$ was $-\mathrm{OH}$.

Besides the well-known bands for the oxides, ${ }^{30}$ two specific bands were chosen to gain insights about the surface persistence of the additive molecules. One was the band assigned to $\mathrm{CH}_{3}$ bending vibrations (at $1385 \mathrm{~cm}^{-1}$ ), while the other one was a complex signal formed from $\mathrm{N}-\mathrm{H}$ deformation (more precisely of $\mathrm{NH}_{2}$ at $1630 \mathrm{~cm}^{-1}$ ) and/or amide $\mathrm{C}=\mathrm{O}$ stretching (1690-1630 $\left.\mathrm{cm}^{-1}\right)$ and/or ketone $\mathrm{C}=\mathrm{O}$ stretching $\left(1750-1680 \mathrm{~cm}^{-1}\right)$. The $\mathrm{C}=\mathrm{S}$ band was not detectable as it was in the zone where the semiconductor has its own characteristic bands $(\mathrm{C}=\mathrm{S}$ stretching at $732 \mathrm{~cm}^{-1}$ ).

Our hypothesis was that if Triton-X plays an important role in the shape-tailoring, then it should show a significant amount of remnant $\mathrm{CH}_{3}$ associable bands $\left(1385 \mathrm{~cm}^{-1}\right)$ on the surface of the obtained semiconductor material. Analogue presumptions were made for all the specific additives used so far in the present work (for the additives with different polarity, the complex signal was followed at $1630 \mathrm{~cm}^{-1}$ ). However, a stand-alone interpretation of the above-mentioned IR signals was not carried out, as information for doing so was lacking, which is why the intensity ratio of the two bands were considered $\left(I_{1385} / I_{1630}\right)$, which may also show the impact ratio of the two types of additives. The following very important observations were noticed:

- When Triton X-100 was applied, the $\mathrm{CH}_{3}$ bending vibrations (at $1385 \mathrm{~cm}^{-1}$ ) were very intense in all the cases, giving higher values for the $I_{1385} / I_{1630}$ band ratios.

- When Triton-X-100 was missing, the above-mentioned ratio was lowered or even dropped drastically.

- A surprisingly low $I_{1385} / I_{1630}$ intensity ratio was obtained for sample AC, whereas a high value was expected due to the usage of acetone as the shape-controlling agent - an observation which can be most likely explained by the fast evaporation of acetone from the surface.

- The highest values of $I_{1385} / I_{1630}$ were obtained for AA + TRX, U + TRX, G + TRX. FA + TRX and A + TRX. 

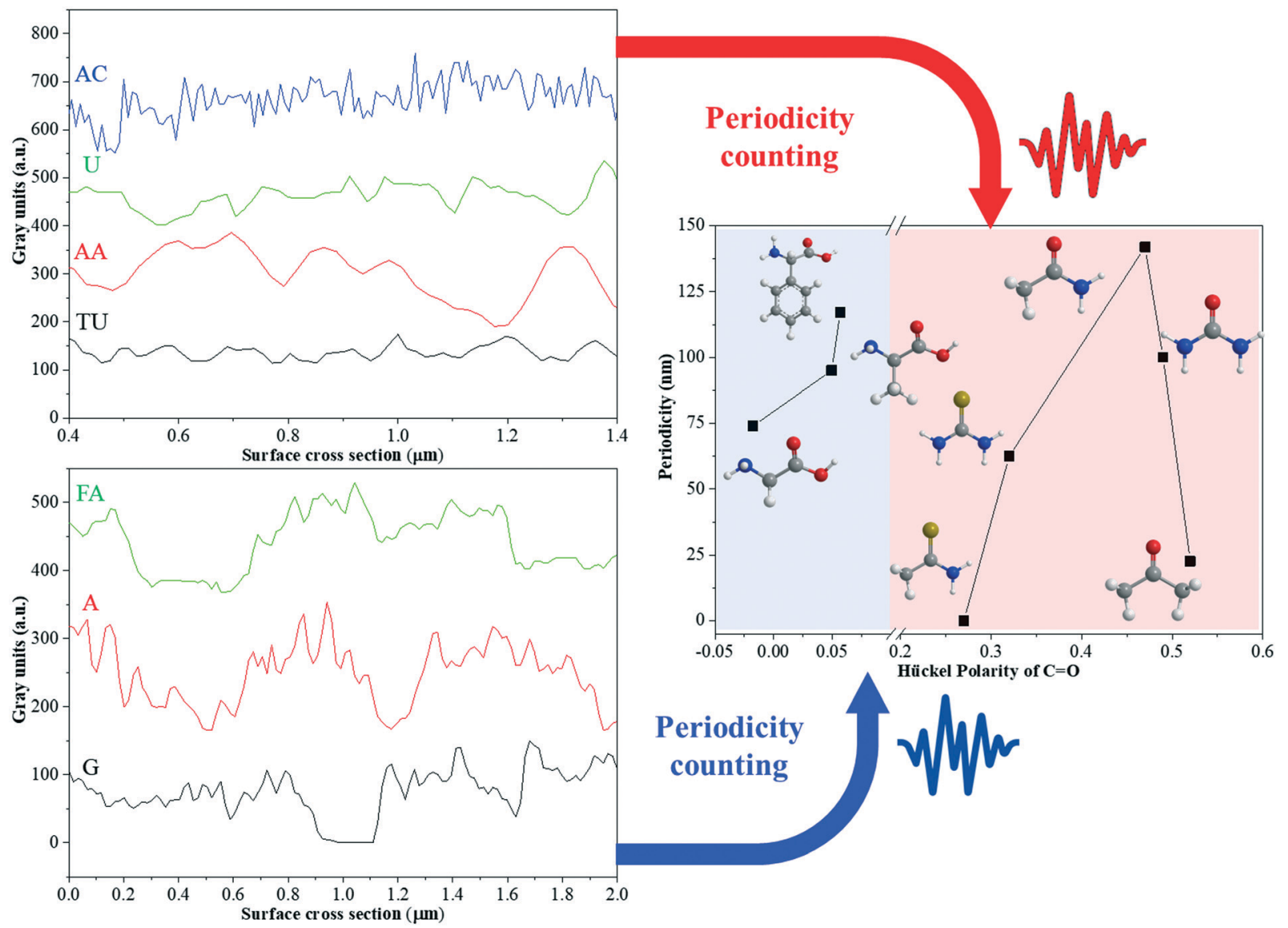

Fig. 10 Correlation of surface roughness with the polarity of the additive molecules.

The above-listed observations clearly emphasize that the presence of Triton X-100 could be demonstrated indeed, which it was also found to be responsible for the formation of the rose shape. Without Triton $\mathrm{X}-100$, the intensity ratio of the two selected bands, that is, 1385 and $1630 \mathrm{~cm}^{-1}$,

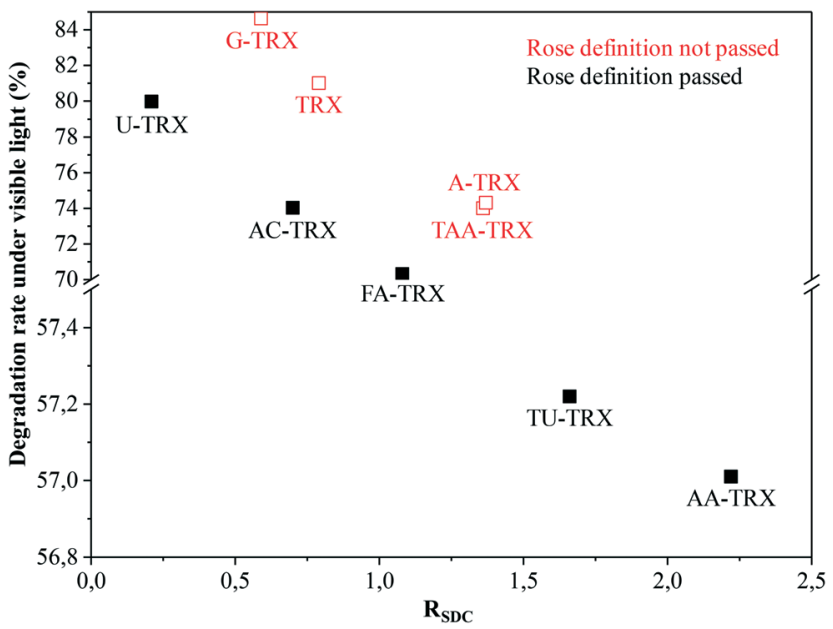

Fig. $11 R_{\mathrm{SDC}}$ value and the visible light degradation yields' relationship. Even non-rose-like crystal shapes obey the $R_{\mathrm{SDC}}$-photoactivity trend, pointing out a clear dependence of the activity on the morphology and nevertheless on the structure of the shape-tailoring agents. corresponded nearly with the activity trends measured in UV or visible light for the appropriate samples, showing that the Hückel polarity of the additives was directly related with their anchoring capacity. More precisely, as the Hückel polarity of the chalcogen-oxygen double bond increases, the anchoring grade of the shape-tailoring compound decreases (Fig. 12).

\section{Conclusions}

In the present work, a new type of approach was developed considering the shape-tailored synthesis of photocatalytic materials. To do this, we successfully obtained $\mathrm{Bi}_{2} \mathrm{WO}_{6}$ hierarchical microstructures and evaluated their visible and UV light activity. To get a clear understanding regarding the relationship between the structure of the shape-tailoring agent, two Hückel polarity series were chosen: in the first one, the chalcogen atom ( $\mathrm{O}$ and $\mathrm{S}$ ) and methyl and amine groups were systematically changed, while in the second one, a series of amino acids were considered in which glycine was derived to alanine and phenylalanine to investigate the importance of the carbon chain length in terms of the polarity. Moreover, the impact of Triton X-100 was also experimented with.

A series of chain correlations were found. It was proven that as the polarity of the carbon chalcogen bond decreases, the activity of the semiconductor decreases as well. With the 
a.)

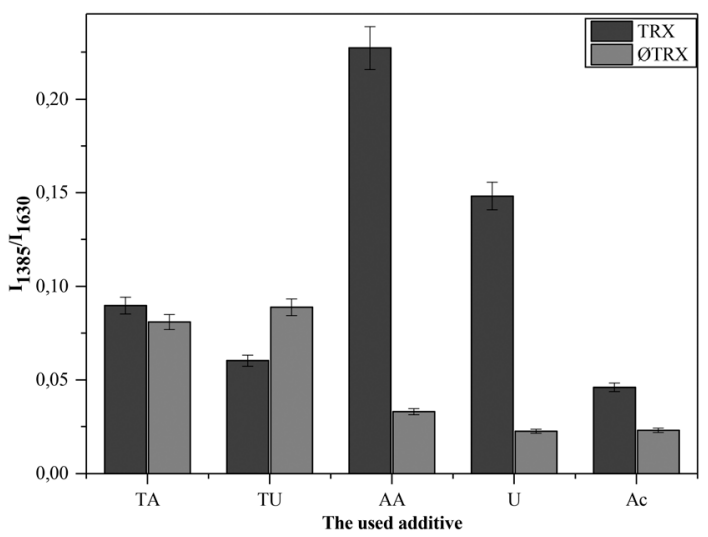

b.)

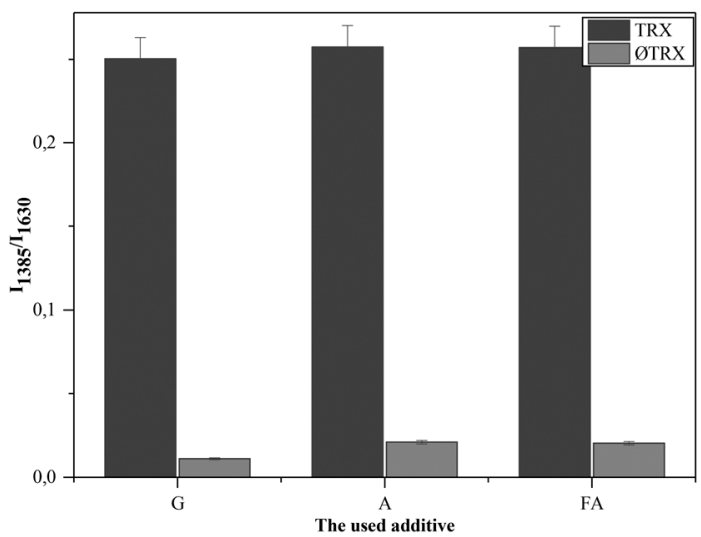

Fig. 12 IR band ratio values $I_{1385} / I_{1630}$ obtained from the IR spectrum of the individual materials. Two series are shown here: the different amides, thioamides series (a) and amino acid series (b).

addition of Triton $\mathrm{X}-100$, this trend was destroyed. An increasing trend for $\mathrm{d} R / \mathrm{d} \lambda$ was also found in this case. In the case of the amino acids, the same decrease was observed as a function of the polarity.

Clear morphology-Hückel polarity relationships were uncovered in the terms of the crystal periodicity, showing that the individual crystallites forming the hierarchical shape showed a gap, which was dependent on the applied agents' structure. As in this correlation, the materials obtained with the presence of Triton X-100 did not fit in with this; therefore a new approach was developed and then quantified as the rose similarity decay constant $\left(R_{\mathrm{SDC}}\right)$. This constant showed that, as the obtained geometry showed a lower $\left(R_{\mathrm{SDC}}\right)$ value, so its visible activity lowered. This empirical function created a direct bridge between the morphology and activity, governed by the polarity of the shape-controlling molecules, which were proven to be anchored on the surface of catalysts. Furthermore, it should be also noted that this graphical approach does not give insights concerning the real structural entities responsible for any of the observed properties, and does not replace classical valid in-depth investigations. However, the method gives a direct way to perform the verification of the existence of a morphology-activity relationship.

\section{Conflicts of interest}

There are no conflicts to declare.

\section{Acknowledgements}

The financial support for Zsolt Kása was provided by the Campus Mundi Programme (EFOP-3.4.2-VEKOP/15-201500001) and the Hungarian-Indian TéT project TÉT_15-IN-12016-0013. The authors would like to thank the financial support by the GINOP programme (GINOP-2.3.2-15-2016-00013) as well for the funding obtained from GTC-31805/2016 research grant for young researchers provided by the BabeşBolyai University.

\section{Notes and references}

1 T. Gyulavári, Zs. Pap, G. Kovács, L. Baia, M. Todea, K. Hernádi and G. Veréb, Catal. Today, 2017, 284, 129-136.

2 H. Kazuhito, I. Hiroshi and F. Akira, Jpn. J. Appl. Phys., 2005, 44, 8269.

3 H. Zhang, G. Chen and D. W. Bahnemann, J. Mater. Chem., 2009, 19, 5089-5121.

4 S. Sakthivel, B. Neppolian, M. V. Shankar, B. Arabindoo, M. Palanichamy and V. Murugesan, Sol. Energy Mater. Sol. Cells, 2003, 77, 65-82.

5 A. McLaren, T. Valdes-Solis, G. Li and S. C. Tsang, J. Am. Chem. Soc., 2009, 131, 12540-12541.

6 W. S. Kuo and P. H. Ho, Chemosphere, 2001, 45, 77-83.

7 R. Asahi, T. Morikawa, T. Ohwaki, K. Aoki and Y. Taga, Science, 2001, 293, 269-271.

8 R. Thiruvenkatachari, S. Vigneswaran and I. S. Moon, Korean J. Chem. Eng., 2008, 25, 64-72.

9 Z. Jiang, F. Yang, N. Luo, B. T. T. Chu, D. Sun, H. Shi, T. Xiao and P. P. Edwards, Chem. Commun., 2008, 6372-6374.

10 Q. Zhang, Y. Li, E. A. Ackerman, M. Gajdardziska-Josifovska and H. Li, Appl. Catal., A, 2011, 400, 195-202.

11 A. G. Thomas and K. L. Syres, Chem. Soc. Rev., 2012, 41, 4207-4217.

12 H. Fu, L. Zhang, W. Yao and Y. Zhu, Appl. Catal., B, 2006, 66, 100-110.

13 H. Xie, D. Shen, X. Wang and G. Shen, Mater. Chem. Phys., 2007, 103, 334-339.

14 L. Xie, J. Ma, J. Zhou, Z. Zhao, H. Tian, Y. Wang, J. Tao and X. Zhu, J. Am. Ceram. Soc., 2006, 89, 1717-1720.

15 S. Zeng, R. Tang, S. Duan, L. Li, C. Liu, X. Gu, S. Wang and D. Sun, J. Colloid Interface Sci., 2014, 432, 236-245.

16 X. Lin, Z. Liu, X. Guo, C. Liu, H. Zhai, Q. Wang and L. Chang, Mater. Sci. Eng., B, 2014, 188, 35-42.

17 J. He, W. Wang, F. Long, Z. Zou, Z. Fu and Z. Xu, Mater. Sci. Eng., B, 2012, 177, 967-974.

18 J. Xiao, W. Dong, C. Song, Y. Yu, L. Zhang, C. Li and Y. Yin, Mater. Sci. Semicond. Process., 2015, 40, 463-467.

19 Y. Y. Li, J. P. Liu, X. T. Huang and G. Y. Li, Cryst. Growth Des., 2007, 7, 1350-1355.

20 W. Wei, J. Xie, X. Lü, P. B. Osei, Z. Yan, S. Meng and H. Cui, Monatsh. Chem., 2014, 145, 47-59. 
21 M. Aslam, I. M. I. Ismail, S. Chandrasekaran and A. Hameed, J. Hazard. Mater., 2014, 276, 120-128.

22 X. Li, Y. Li, J. Shen and M. Ye, Ceram. Int., 2016, 42, 3154-3162.

23 J. Y. He, W. M. Wang, L. L. Zhang, Z. G. Zou, Z. Y. Fu and Z. Xu, J. Wuhan Univ. Technol., Mater. Sci. Ed., 2013, 28, 231-234.

24 Y. P. Bhoi, D. P. Rout and B. G. Mishra, J. Cluster Sci., 2016, 27, 267-284.

25 S. Yao, J. Wei, B. Huang, S. Feng, X. Zhang, X. Qin, P. Wang, Z. Wang, Q. Zhang, X. Jing and J. Zhan, J. Solid State Chem., 2009, 182, 236-239.

26 A. Phuruangrat, A. Maneechote, P. Dumrongrojthanath, N. Ekthammathat, S. Thongtem and T. Thongtem, Mater. Lett., 2015, 159, 289-292.
27 G. Zhang, Z. Hu, M. Sun, Y. Liu, L. Liu, H. Liu, C.-P. Huang, J. Qu and J. Li, Adv. Funct. Mater., 2015, 25, 3726-3734.

28 C. Li, G. Chen, J. Sun, Y. Feng, J. Liu and H. Dong, Appl. Catal., B, 2015, 163, 415-423.

29 X. Wu, S. Fang, Y. Zheng, J. Sun and K. Lv, Molecules, 2016, 21, 181.

30 Y. Zhao, Y. Wang, E. Liu, J. Fan and X. Hu, Appl. Surf. Sci., 2018, 436, 854-864.

31 D. Flak, A. Braun, B. S. Mun, J. B. Park, M. Parlinska-Wojtan, T. Graule and M. Rekas, Phys. Chem. Chem. Phys., 2013, 15, 1417-1430.

32 Zs. Kása, K. Saszet, A. Dombi, K. Hernádi, L. Baia, K. Magyari and Zs. Pap, Mater. Sci. Semicond. Process., 2018, 74, 21-30. 